\title{
Fats and Fatty Acids in Human Nutrition: Introduction
}

\author{
Barbara Burlingame $^{a}$ Chizuru Nishida $^{b}$ Ricardo Uauy ${ }^{c, d}$ Robert Weisell ${ }^{e}$ \\ ${ }^{a}$ Nutrition and Consumer Protection Division, Food and Agriculture Organization of the United Nations (FAO), \\ Rome, Italy; ${ }^{b}$ Department of Nutrition for Health and Development, World Health Organization (WHO), \\ Geneva, Switzerland; ' Instituto de Nutrición y Tecnología de los Alimentos (INTA), Universidad de Chile, \\ Santiago, Chile; ${ }^{\mathrm{d}}$ Nutrition and Public Health Intervention Research Unit, London School of Hygiene \& \\ Tropical Medicine, London, UK; ${ }^{~}$ Consultant, Nutrition and Consumer Protection Division, Food and Agriculture \\ Organization of the United Nations (FAO), Rome, Italy
}

The Food and Agriculture Organization of the United Nations (FAO) and the World Health Organization (WHO), as technical agencies of the United Nations, are charged with providing science-based guidance on food and nutrition to national governments and the international community. The process used to fulfill this mandate involves systematic reviews of currently available scientific evidence, which often culminate with the convening of joint expert consultations that review the state of scientific knowledge, deliberate the issues, and translate this knowledge into the definition of requirements, the nutritional requirement values and corresponding nutrient-based recommendations. The overall goal of these recommendations is to support the health and nutritional well-being of individuals and populations. Topics recently covered include energy, protein and amino acids, fats and oils, and the majority of vitamin and minerals in addition to carbohydrates with the objective of providing guidance on their requirements and recommended dietary intakes.

The most recently convened expert meeting was the Joint FAO/WHO Expert Consultation on Fats and Fatty Acids in Human Nutrition, held in Geneva, Switzerland, November 10-14, 2008. This consultation was the third to be held on the subject of fats in human nutrition, with the first expert consultation on this topic held in 1977 [FAO, 1977] and the second in 1993 [FAO, 1994].
There have been a number of major developments in this field over the past 15 years, with a resulting need to update the 1996 publication and recommendations. A large number of population-based cohort studies and randomized control trials have been conducted that address the impact of fats, and specifically different fatty acids, on health. Knowledge of the role of particular fatty acids in determining health and nutritional well-being and how they exert these effects has expanded dramatically. We now have a better understanding of how they are metabolized in the body, how they control gene transcription and expression, and how they interact with each other. Fats and fatty acids should now be considered as key nutrients that affect both early growth and development, as well as nutrition-related chronic diseases later in life. The benefits and potential risks of these nutrients go well beyond their role as fuels: specific $n-3$ and n-6 fatty acids are essential nutrients, while others affect the prevalence and severity of cardiovascular disease, diabetes, cancer and age-related functional decline. This makes the process of defining requirements and recommendations more complex, and demonstrates the need to focus on the role of individual fatty acids and how requirements vary with age and physiological status.

With respect to the recommendations of the previous 1993 consultation [FAO, 1994], the 2008 consultation

\begin{tabular}{ll}
\hline KARGER & (c) 2009 S. Karger AG, Basel and FAO \\
0250-6807/09/0553-0005\$26.00/0 \\
$\begin{array}{l}\text { Fax +41 61 306 1234 } \\
\begin{array}{l}\text { E-Mail karger@karger.ch } \\
\text { www.karger.com }\end{array}\end{array}$ & $\begin{array}{l}\text { Accessible online at: } \\
\text { www.karger.com/anm }\end{array}$
\end{tabular}


placed more emphasis on the role of certain fatty acid categories, an example being the convincing role played by long-chain polyunsaturated fatty acids in neonatal and infant growth and development, as well as a beneficial role in the maintenance of long-term health and prevention of some chronic diseases. There was strong 'convincing' evidence to recommend a reduction in trans fatty acids due to an increased risk of developing coronary heart disease and adverse blood lipid changes, including increasing LDL concentrations and adverse changes in the total/LDL-cholesterol ratio.

The timeliness of this expert consultation is also tied to the clear recognition of the increasing global burden of chronic disease. Recent work by the FAO and WHO related to this issue include: the 2002 expert consultation on 'Diet, nutrition and the prevention of chronic diseases' [WHO, 2003], the 2001 expert consultation on 'Human energy requirements' [FAO, 2004] and its companion 2002 expert consultation on 'Protein and amino acid requirements in human nutrition' [WHO, 2007], a 2002 technical workshop on 'Food energy - methods of analysis and conversion factors' [FAO, 2003], and several scientific updates; one by the FAO/WHO in 2006 on carbohydrates in human nutrition [Nishida et al., 2007] and another by the WHO on trans fatty acids [Nishida and Uauy, 2009]. To varying degrees, these integrated efforts provide the scientific basis for strategies, programs and projects of the FAO, WHO and their member countries.

During the past 15 years, the changes in diets and lifestyles resulting from industrialization, urbanization, economic development and market globalization have increased rapidly, particularly in developing countries where rapid socioeconomic changes are occurring. Whereas improvements in the standard of living have been observed, this has often been accompanied by unhealthy dietary patterns and insufficient physical activity to maintain energy balance and a healthy weight. The net result has been an increased prevalence of diet-related chronic diseases in all socioeconomic groups; these conditions now represent the main cause of death and disability on a global basis.

Fats are energy dense ( $37 \mathrm{~kJ}$ or $9 \mathrm{kcal}$ per gram), provide the medium for the absorption of fat-soluble vitamins, are a primary contributor to the palatability of food, and are crucial to proper development and survival during the early stages of life - embryonic development and early growth after birth - on through infancy and childhood. Thus, the greater need for fatty acids during pregnancy and lactation is highlighted. The n-3 long- chain fatty acids provide the structural basis for the development of the brain and central nervous system. In contrast, the high intake of saturated fatty acids, and to an even greater extent trans fatty acids, substantially contributes to the development of cardiovascular diseases. These claim many lives not only in affluent societies, but now they are also the main cause of adult death in both developed and developing countries.

In preparing and conducting the Joint $\mathrm{FAO} / \mathrm{WHO} \mathrm{Ex}$ pert Consultation on Fats and Fatty Acids in Human Nutrition, the 'Framework for the provision of scientific advice on food safety and nutrition' [FAO/WHO, 2007] was followed. The process of selecting experts began with a call for experts that was posted on both the FAO and WHO websites and publicized through numerous channels, including the network of the UN Standing Committee on Nutrition. All applications were reviewed by a panel of four persons, consisting of one member each from the FAO and WHO and two independent outside experts designated by the FAO and the WHO secretariat. Each application was evaluated carefully, and ranked based on the combination of the applicant's educational background and field of expertise, including scientific publications and membership or participation in scientific panels related to the subject of the expert consultation. After initial evaluation to identify qualified candidates, geographic and gender balance and a mixture of scientific areas of expertise were considered in order to arrive at the final selection. In addition, all experts and authors were required to complete a 'declaration of interest' so as to judge any conflicts of interest or perceived conflict of interest regarding their positions or opinions on certain issues.

Background papers for the expert consultation were commissioned after an extensive review of the topics covered in the two previous expert consultation reports and consultation with experts on additional issues and topics that needed to be addressed given the availability of new scientific evidence. This resulted in 13 background papers, which are published in this special topic issue. In developing the conclusions and recommendations, the authors of the background papers were asked to use the four criteria levels (convincing, probable, possible or insufficient) for the 'strength of evidence' developed and applied by the Joint WHO/FAO Expert Consultation on 'Diet, nutrition and the prevention of chronic disease' [WHO, 2003]. The strength of evidence was also reviewed and evaluated during the expert consultation to arrive at conclusions and recommendations and establish fats and fatty acids requirement levels. 
All the background papers were peer reviewed by at least three experts before being forwarded to the expert consultation for review and deliberations. In addition, all the papers were reviewed by the consultation experts before convening. It should be noted, however, that these papers do not represent the final conclusions of the FAO/ WHO Expert Consultation.

With the upcoming International Congress on Nutrition in Bangkok in early October 2009, the FAO and WHO decided, in collaboration with S. Karger AG publishers, to produce a special topic issue to the Annals of Nutrition and Metabolism that contains all the background papers prepared for the Joint FAO/WHO Expert Consultation on Fats and Fatty Acids, with the hope of providing a useful research and reference source.

\section{Acknowledgement}

Special acknowledgement and appreciation is expressed to Gina Kennedy who served tirelessly organizing both the preparation of the background papers published in this special topic issue and the expert consultation itself.

\section{Disclosure Statement}

Dr. Burlingame has nothing to disclose. Dr. Nishida has nothing to disclose. Dr. Uauy has served as an ad-hoc technical consultant for Bristol-Myers Squibb and currently for Cadbury; in addition he serves as an ad-hoc consultant for Bimbo Mexico and Kellogg's in advising on scientific awards and prizes related to nutrition. Dr. Weisell has nothing to disclose.

\section{References}

FAO: Report of a joint FAO/WHO expert consultation on dietary fats and oils in human nutrition. FAO technical papers 3. Rome, FAO, 1977.

FAO: Fats and oils in human nutrition: report of a joint $\mathrm{FAO} / \mathrm{WHO}$ expert consultation. $\mathrm{FAO}$ technical papers 57. Rome, FAO, 1994.

FAO: Food energy - methods of analysis and conversion factors: report of a technical workshop. FAO food and nutrition paper 77. Rome, FAO, 2003.
FAO: Human energy requirements: report of a joint $\mathrm{FAO} / \mathrm{WHO} / \mathrm{UNU}$ expert consultation. FAO food and nutrition technical report series 1. Rome, FAO, 2004.

FAO/WHO: Framework for the provision of scientific advice on food safety and nutrition. FAO, Rome \& WHO, Geneva, 2007.

Nishida C, Uauy R: WHO scientific update on trans fatty acids (TFA). Eur J Clin Nutr 2009; 63(suppl 2).
Nishida C, Martinez Nocito F, Mann J: Joint $\mathrm{FAO} / \mathrm{WHO}$ scientific update on carbohydrates in human nutrition. Eur J Clin Nutr 2007;61(suppl 1).

WHO: Diet, nutrition and the prevention of chronic diseases. WHO Technical Report Series 2003, p 916.

WHO: Protein and amino acid requirements in human nutrition: report of a joint $\mathrm{FAO} /$ WHO/UNU expert consultation. WHO Technical Report Series 935. Geneva, WHO, 2007. 